\title{
1. Introduction: The sociology of the family - towards a European perspective
}

\author{
Norbert F. Schneider and Michaela Kreyenfeld
}

\section{ON THE WAY TO A EUROPEAN FAMILY SOCIOLOGY?}

Most European countries have their own traditions that define the areas and topics of family sociology (for France, see Déchaux 2009; for Germany, see Fasang et al. 2016; Konietzka et al. 2020; for Italy, see Saraceni and Naldini 2013). However, it has been less clear what constitutes 'European family sociology', and whether such a classification would be reasonable in a time when research is becoming more collaborative, and is often geared towards publications in international, and particularly United States-based, top journals. Nonetheless, a number of trends have become apparent that suggest that there has been a significant change in the research landscape that may eventually lead to the development of a unique European family sociology.

Until the 1990s, sociological studies on the family were often limited to the national context. Moreover, they were predominantly written in the national language, particularly in the larger European countries, such as Germany, France, and Italy. Since then, research has moved beyond the narrow national context. It has 'internationalised', in the sense that both international comparative family research and international cooperation and exchange have become common. An increasing share of sociological research is being carried out by research groups made up of scholars from multiple countries. Large-scale comparative data projects - such as the Family and Fertility Surveys and its successor the Generations and Gender Survey, as well as the Survey of Health, Aging and Retirement in Europe - have all advanced comparative work on European family behaviour. As a result of such projects, we have become more aware of the peculiarities of family behaviour and patterns of single countries. This awareness has sharpened our perspectives, forced us to think beyond our respective national contexts, and raised the question of whether findings are transferable across countries. The European context has also been a source for theorising about family behaviour. The second demographic transition (SDT) theory and the comparative welfare state approach are two key and prominent examples of theories that have clearly evolved in response to the family developments in European countries (see Nauck as well as Neyer in this volume).

The aim of this research handbook is to provide a state-of-the art account of European family sociology. We discuss landmark theories, illustrate major trends, and introduce the reader to established and innovative methods for describing and analysing the complexities in family behaviour and family patterns in European countries. Our hope in doing so is that this research handbook will contribute to the further establishment of a European family sociology. In this chapter, we seeks to answer the following questions: How has European family sociology developed in recent decades? What are the key topics in the field, and how have they been changing over time? What relevant topics may have been neglected? What are the theoretical innovations in the field? What are the methodological challenges? How much 
does progress in the field depend on data availability? What are, more generally, the avenues for future research?

\section{A SHORT ACCOUNT OF THE MAIN OBJECTIVES OF FAMILY SOCIOLOGY}

\subsection{Family Change in Europe}

European families are undergoing a process of profound change. In addition to the changes that are occurring in family forms, family behaviour, and family dynamics, the relationship between the family and society is undergoing a process of transformation. At the core of this shift is the transition away from the family representing a social institution with roles and functions and towards the emergence of a community of individual responsibility and group solidarity that is considered worthy of support (Schneider 2012). For several decades, the main topics that have been addressed in applied family research include the diversity of living arrangements, the increase in non-marital births, late home-leaving, the postponement of first childbearing, childlessness, and divorce and separation. The analysis of internal structures and relationships between family members - within and, more recently, beyond the household context - has also always been a part of mainstream family sociology. The division of care and housework within the household context is probably the most prominent theme in this area of research (see Grunow; Evertsson et al. as well as Sullivan in this volume). Such processes have been triggered and shaped by a number of factors, including the still ongoing increase in the labour market participation of mothers and related shifts in the participation of fathers in family and care work (see Matysiak and Cukrowska-Torzewska in this volume). Beyond those topics, scholars have increasingly been investigating intergenerational relationships, including parent-child relationships, as well as relationships between grandparents and grandchildren (see Skopek as well as Zartler in this volume). Many of these studies have concluded that relationships in families - that is, between parents and children, as well as between partners - have become less hierarchical, and more egalitarian.

Many of the above-mentioned trends have been moving in similar directions in most European countries. There are, however, major differences in the onset and the pace of the development of these trends. This is probably most obvious in the case of non-marital childbearing, for which we have comparable data across countries and can identify clear regional patterns, with the Nordic countries being the vanguards and the rest of Europe lagging behind. Divorce rates have been following a similar pattern, with Ireland, Malta, and some Eastern and Southern European countries being the laggards in this development. More recently, however, reversals of these trends have been documented (see Sobotka and Berghammer as well as Berrington in this volume). There is, for example, evidence that non-marital birth ratios are stagnating or falling slightly in the Nordic countries and France, and that the divorce rates are declining in some European countries. It is too early to tell whether these developments are indeed initial indications of trend reversals, or are, rather, indicative of a 'stable state' characterised by high rates of separation and high ratios of non-marital births. Regardless of how they are interpreted, these developments clearly challenge existing theories and perceptions of a unidirectional trend in family behaviour. 
There are also more recent developments that are increasingly attracting attention in family research. Major shifts in family structures and family behaviour after separation and divorce have been documented (Mortelmans and Zartler in this volume). Fathers remain more involved in their children's lives after separation and divorce than was the case in previous decades. Indeed, the shift towards joint residence becoming more common calls into question previously uncontested categories, such as single and non-residential parenthood. These changing residence patterns have also challenged prior research on family forms, which was often restricted to the household context (see Widmer in this volume). In the same vein, the importance of 'multi-locality' is growing. This also pertains to the analysis of the family behaviour of migrant and 'transnational' families (see Merla et al. in this volume).

Some scholars have observed an 'intensified' approach to parenting, with unclear consequences for children's educational outcomes and social inequality between children and families. At the same time, the growing awareness of child well-being has been accompanied by a strengthening of the legal position of children and child well-being in national and supranational legislation (such in Article 24(2) of the Charter of Fundamental Rights of the European Union). Another important development concerns relations within families, including changes in parenting styles and objectives. Intergenerational relations in contemporary Europe can be regarded as harmonious and low conflict, which is not a phenomenon that can be taken for granted given the longer historical context. Previously, family and ageing research were generally seen as separate spheres of investigation. However, changes in family behaviour at older ages are increasingly straddling these two areas of inquiry (see Dykstra in this volume). An example of research that touches on both spheres is the study of 'grey divorce'.

Family research is also clearly affected by mega-trends, such as the 'digitalisation' of our society. Digital trace and social media data are potential sources for innovative family research that have yet to be tapped (see Legewie and Fasang in this volume). Digital communication and smartphone usage also have profound implications for family life, family relations, and child well-being that have yet to be fully examined by family scholars. Medically assisted reproduction (MAR) is another 'technology-induced' topic, which, in recent years, seems to have developed into an established research field at the intersection of family sociology and medical research (see Passet-Wittig and Bujard in this volume). A significant societal development that we were unable to cover in this research handbook is the Covid-19 crisis, and how it is affecting family relationships and family behaviour. The large body of literature that has already been published on the pandemic up to today (August 2020) is indicative of how family researchers work. It shows that family researchers can quickly bundle their resources and focus their attention and research interests more decisively on current trends and socio-political challenges than they could in the past.

\subsection{Changing Objectives of Family Sociology}

The scope of family sociology has expanded considerably over the past 30 years. Until the 1980 s, it was common practice in mainstream family sociology to focus on the married family. Single motherhood was researched, but regarded as an 'incomplete family' that lacked the male guardian. Married stepfamilies were also regarded with a certain degree of suspicion. Since then, four lines of development in the field can be identified: an increase in research activities on living arrangements beyond the nuclear family; a move away from purely household-oriented and towards network-oriented family studies; greater consideration 
of the process-oriented dimension of family, including of partner choice (Van Bavel in this volume); and a significant increase in research on internal family structures, instead of on mere morphology.

Associated with these extensions of the subject area, which often occurred only gradually, is a shift in the 'idea' and definition of the family. For a long time, the prevailing view was that a family consists of a married couple who live together with their children in a single household unit. Groups of people in other living arrangements were not regarded as families, and thus were not the core subject of family research. The subject area of family sociology has expanded since then, as the family is increasingly defined as a community of responsibility and care that extends beyond the boundaries of household, marriage, kinship, and even parenthood. In addition, it has been argued that the family should be understood not only as a structural form, but as a dynamic process that is shaped by a series of transitions, and the resulting phases and breaks. The complexity and the diversity of family dynamics is the focus of research today, rather than the old-fashioned model of the rigid and structured family cycle (Glick 1955; see also Konietzka and Kreyenfeld in this volume). Nowadays, purely morphological studies about the size and the composition of families and kinship relations between family members are rare in family sociology. The structure-related studies that are now being published focus less on the external structural characteristics of families, and more on the internal structures within families: namely, the relationships between partners, between parents and children, and with grandparents.

In the course of the shift towards process-oriented family considerations, the perception that after a separation a family is transformed into a post-separation family, and sometimes into a stepfamily, has become widely prevalent. This is associated with the idea that the family transforms or continues following a divorce or separation, rather than terminates. If there are children in the family, the family does not end with the divorce or separation of the parents, but instead becomes more complex and 'branched'. Post-separation families have always been connected through continuing financial obligations, such as child alimony and ex-spousal support. However, the bonds, relationships, and obligations among the family members become stronger and more complex through the joint care and residence of the children. As a consequence of these joint residence and care arrangements, many new questions and challenges regarding the legal regulation of post-separation family lives have emerged (see Zartler in this volume). Several countries have made progress on these issues, and support joint parenting in their legal framework. Other countries are still laggards in this respect. Even if there are laws that regulate family arrangements after a separation, the ex-partners face considerable challenges in coordinating the care and education of their joint children, and these arrangements are often the subject of intense, ongoing conflicts. However, there has been little comparative empirical research on the structures and relationships of such post-separation families. Moreover, relatively few studies have examined how these post-separation legal arrangements, such as child alimony and legal or physical custody, shape the family behaviour and well-being of post-separation families in European countries.

Another important feature of the recent changes in family research is the change in the concept of family: i.e., from being to doing family. This shift in research subjects has also been accompanied by a change in research topics. Today, social positions within families and their functions are seldom studied, but analyses of the relationships between family members are becoming increasingly common. The idea that the family is a social institution or a social system, as was long assumed in research based on the functionalist perspective (Parsons 1955), 
is being replaced by the idea that families are forms of relationships and ways of life that are constantly being individually formed and shaped (Cherlin 2006; West and Zimmerman 1987). The most concise description of this change in perspective is that the institutional 'being family' is turning into the action-oriented 'doing family', or that role theory is being replaced with actor orientation. Especially in German-speaking family sociology, the concept of 'doing family' is prominent (Jurczyk et al. 2014). Given this increasingly pronounced action orientation in family sociology, it is not surprising that family research based on role theory, which dominated until the 1980s (Dahrendorf 1965), has now almost completely disappeared. In contrast, studies that assume that families act in rational and benefit-oriented ways have become increasingly common, and often rely on standard household economics (for a critical view, see Sigle in this volume). There are numerous studies in family sociology (and family economics) that analyse the division of household labour using bargaining models (Bittman et al. 2003; Lundberg and Pollak 1984; see also Grunow in this volume).

Since the 1980s, the main empirically verifiable structural change in the family has been interpreted as a transition away from the nuclear family, which had been seen as the "normal family'; and towards a diversity of family forms. There are two main competing interpretations of this change: the crisis theorem and the resilience theorem. Advocates of the crisis theorem interpret the change as the disappearance of the 'normal family', and highlight the negative repercussions family change has had for child development and social cohesion (McLanahan 2004; Whitehead 1993). Conversely, proponents of the resilience theorem argue that the diversity of family forms and the de-institutionalisation of the family are necessary preconditions for the emergence and stabilisation of open, pluralistic, and democratic societies (Stacey 1996). Inherent in this perspective is the assumption that family diversity is not a new development, but is, as socio-historical family research has shown, a 'return to the normality of family diversity' that has long been a feature of European societies, except perhaps in the heyday of the bourgeois family model, which is generally understood to have occurred between 1950 and 1975 for European countries (see Ehmer in this volume). Even today, the traditional nuclear family - defined as a co-residential heterosexual married couple with biological children who practise a strict division of labour between the male and the female partner - continues to be the reference point in much of our research (see Sullivan as well as Grunow in this volume). This may be explicable for welfare state research, given the path-dependency of political institutions. It is more interesting to observe that other types of research remain centred on a definition of 'normality' that only rarely fits the lived realities of families in contemporary Europe.

\subsection{Methodological Developments}

The expansion of the scope of the subject matter and the changes in the main ideas and definitions of what family means are not the only relevant changes in recent years. Perhaps even more significant for the further development of family research are developments in methods, data, and publication patterns and strategies. In the recent past, the variety of research topics in family sociology has increased tremendously. However, the trend towards a very small-scale differentiation of research questions can be even more clearly observed. One reason for this development is, no doubt, the complete shift in publication behaviour, which is increasingly oriented towards the writing of short empirical papers. Longer articles or even books seem to have fallen out of fashion. The pressure young scientists face to publish quickly, and 
preferably in high-ranking international journals, is enormous, and supports the trend towards publications that address increasingly narrow research questions. This pressure is driving another trend as well. The vast majority of publications are based on large-scale datasets. In quantitative family research, small-scale and topical data collection is considered less important. Due to the content-related limitations, the possible spectrum of research questions is narrowed, since only the topics for which data are available can be researched. However, there are also many benefits related to this development: the availability of large-scale data has clearly advanced the quality of applied family research, and opened up new avenues for undertaking large-scale comparative research projects.

The trend towards improvements in the availability and the quality of data has advanced in tandem with the development of new methods for data analysis. While simple descriptive overviews can be highly influential and have considerable value, they are becoming rare (see, however, Liu and Esteve as well as Skopek in this volume). Large-scale panel studies and wide-ranging, internationally comparative studies currently determine the data landscape. Moreover, in some countries, register data, as well as linked register and survey data, are available. It is, in particular, the availability of large-scale longitudinal data that has led event-history modelling, sequence analyses, and fixed-effects modelling to become part of the standard canon of applied family research. Highly sophisticated methodological procedures and increasingly refined statistical techniques are employed - although it is sometimes doubtful whether the characteristics of the data used actually meet the model requirements. Whereas methodological developments have taken place at an amazing speed, relatively little is being invested in theory development. While quantitative data and studies currently dominate family research, the importance of qualitative and ethnographic research should not be underestimated (see Bernardi in this volume). Qualitative approaches may well receive more attention and consideration in the future, as they can fill in or point out the gaps that quantitative research cannot address.

While panel studies are now common, the importance of multi-actor designs in empirical family research is only gradually being recognised. The idea is slowly taking hold that a considerable proportion of family-relevant events - especially those based on decisions - cannot be attributed exclusively to the actions of a single individual, but should instead be attributed to decisions that are jointly made by couples or other groups of people within the family. It is likely that there will be an increase in the number of studies that explicitly generate such data, either by providing information about other individuals or by interviewing dyads. This development should further strengthen the life course perspective in family research, especially the 'linked lives' perspective (see Konietzka and Kreyenfeld in this volume).

\subsection{Avenues for Future Research}

While not all of the trends in family sociology of the recent past can be regarded as indisputably positive, a huge upswing in interest in family sociology is evident from the output that has been generated in the past decades, which has provided theoretical approaches to and descriptions of family behaviour in European countries. Family sociology has become an established field in European sociology that is 'institutionalised' in the committee 'RC 6 Family Research' of the International Sociological Association. Furthermore, family sociology has advanced because it has become increasingly interdisciplinary, and because it conducts research at the intersection of other research areas and disciplines, including stratification research, ageing, 
family demography, and health. However, there are still many obvious gaps in sociological research that should be closed in the near future. Studies on the topics of emotions and sexuality continue to be severely lacking (see, however, Lenz and Adler in this volume). Similarly, while there has been significant research on family relations, kinship relations - such as sibling relationships and relationships with side relatives, such as uncles and aunts - are rarely the focus of studies. The relationships in post-separation families, as mentioned above, are also significantly under-researched. Despite the burgeoning literature on migration, there is surprisingly little research on the topic of 'migration and the family', or on the family behaviour and family arrangements of migrant families (see, however, Andersson in this volume). There is also a lack of quantitative data on migrants that can be used to perform fine-grained analyses of family behaviour by migrant subgroups, which are becoming increasingly important given the growing heterogeneity of migrant populations. Likewise, there has been little research on the topics of socialisation and family and generational relations in old age. In order to close these research gaps, more multi-disciplinary research will be needed, as, for example, Fasang et al. (2016) has called for. In the course of the aforementioned trend towards the partialisation of research topics, studies that address the relationship between family and society or the interactions between family and social systems (such as labour market, education, and child care) have moved into the background. However, such studies are indispensable for providing us with a better understanding of the causes and the consequences for society of changes in family behaviour and family patterns. We expect that family sociology will address the network perspective (see Viry and Herz in this volume) more in the coming years than in the past. In connection with mobility and migration, transnational families will increasingly come into focus (see Merla et al. in this volume). While dyadic data have been collected, there is certainly more scope for examining and understanding how life courses are linked, and how seemingly 'joint decisions' are made. In addition, the child's perspective is gaining in importance, particularly with regard to studies on post-separation family life and family well-being.

We also expect to see further developments in data availability and data generation. Online supported surveys, which can be conducted cheaply and quickly, will gradually push classic survey methods, such as face-to-face surveys, into the background. The wider availability of register data and linked register and survey data may also fuel developments in the area of family research. While 'big data' have reconfigured research in many subject areas and disciplines, it seems that this process has been more gradual in family sociology. However, there is considerable potential for using digital trace and social media data in family sociology. The even more fine-grained capabilities of geo-referencing - i.e., the feeding of spatial information into a dataset - will allow for more refined, regionally differentiated analyses to be conducted. These technological advancements will clearly affect future research on the family as well. Artificial reproductive technologies (ART) and its consequences is already an established area of research (see Passet-Wittig and Bujard in this volume). The mega-theme of 'digitalisation' intrudes on family sociology through the many consequences smartphone and internet usage have for family life, family relationships, and child development. Digitalisation has also transformed the labour market, which has repercussions for family life. The Covid-19 crisis has sharpened our awareness of the opportunities and the pitfalls of home office and telework for combining work and family life. A number of scholars have already started researching these topics, often with the aim of producing social policy-relevant research findings.

More generally, European family sociology is increasingly attracting attention and interest outside the scientific community. To further strengthen the scope and scientific relevance 
of family sociology, efforts should be made to expand its interfaces with related disciplines, particularly family demography, family psychology, epidemiology, health, and life course sociology. Building a stronger theoretical foundation for family sociology also appears to be desirable.

\section{CONTENT OF THIS HANDBOOK}

This handbook is organised into an introduction (Part I) and seven further parts. Parts II and III contain overview chapters that summarise classical as well as novel theoretical perspectives. The following parts address the topics we consider to be most important in contemporary family sociology: family diversity (Part IV), family transitions (Part V), intimate and intergenerational relationships (Part VI), and the division of work and household tasks (Part VII). Part VIII introduces readers to timely topics that raise important social policy concerns: namely, the regulation of assisted reproduction, child poverty, and the organisation of family life across national borders.

\subsection{Theoretical Advances in Family Research}

With its diverse social policies and cultural contexts, Europe is a unique laboratory for exploring the relationship between institutional factors and family behaviour. It comes as no surprise that the grand theories of family sociology, which focused on the interplay of context and behaviour, were inspired by the developments in European countries. The SDT theory is probably one of the most influential and most frequently cited approaches that aimed to describe and provide a theoretical foundation for the family changes that occurred in the second half of the last century in European countries, and that are, in part, continuing until the present day (Lesthaeghe 1995, 2010; Lesthaeghe and Surkyn 1988; Van de Kaa 1987). It has been rightly pointed out that the SDT theory is not a sociological concept, and may not even qualify as a theory in the first place (Coleman 2004). Nonetheless, the SDT approach borrows heavily from sociological theory, and it has drawn our attention to how cultural change - or, rather, 'individualisation' - transforms family behaviour. Another grand theory, which is also intangibly related to the developments on the European continent, is the comparative welfare state approach. Again, this approach may not be regarded as a core sociological concept. It is, rather, situated at the intersection of political science and sociology. Regardless of its disciplinary home, this theory has been one of the most influential works in the area of family sociology, as it filled an important void: i.e., it provided a framework for conceptualising how the social policy context mattered for family decisions and family well-being.

Gerda Neyer's chapter introduces the reader to the welfare state approach. She reminds us that the modern welfare state has always been concerned with the well-being of families. From early in its history, important welfare state measures, such as survivors' pensions, protected the family from the adverse consequences of the loss of the male breadwinner. Surprisingly, comparative welfare state research was fairly late in integrating the pivotal role of the family into the conceptual framework. Since then, however, the triad of market, state, and the family - as well as the distinction between 'familialistic' and 'de-familialising' policies - are the well-known pillars of this framework (Esping-Andersen 1999; Lewis 1992; Sainsbury 1996). While this welfare state framework was subject to severe criticism - in particular because of its 
oversimplified categorisation scheme - the chapter by Neyer illustrates that these early works were foundational, as they defined a new paradigm. Instead of simply analysing single policies, the welfare state approach alerted us that we have to take a comprehensive perspective and examine the interplay of different policies if we want to understand family behaviour. The chapter also draws attention to new avenues for research in the area of welfare state research. The varieties of capitalism approach sheds more light on the roles of firms, trade unions, labour rights, and labour relations in the provision of welfare. Thus, the varieties of capitalism approach fills a gap that the classical welfare state approach left open. However, Gerda Neyer points out that more effort is needed to systematically integrate the role of the family into this framework. This is also the case for the social investment approach, which highlights that new social risks - most prominently, the Covid-19 crisis - reconfigure societies and welfare states. However, the social investment approach also needs to become more comprehensive by including the family in the production of welfare and in the amelioration of social risks.

The chapter by Bernhard Nauck adopts a cross-cultural perspective. It starts on a critical note, reminding us that prior research in this area was subject to certain 'xenological tendencies'. While scholars that study behaviour in western societies mainly do so through the lens of rational decision making, investigations of non-western societies frequently take a 'cultural turn'. Scholars often label their research as a 'cultural study' when the investigation involves a non-western society, regardless of whether several or only one country is being investigated. The chapter emphasises that any real 'cross-cultural approach' requires the comparison of at least two societies. Furthermore, a close examination of how the institutional fabric of a society is interwoven with the actual family behaviour is needed. The classical example of this type of research is the study of the historical differences in family patterns between Eastern and Western Europe. The patrilineal inheritance rules in western societies are closely linked to family behaviour and family structures - including the dominance of the neolocal family that prevail in Western Europe (see also Ehmer in this volume). The chapter also challenges the grand theories of family sociology, including the above-mentioned SDT approach. Nauck raises concerns not only about the teleological perspective that characterises this approach, but about its simplified view of what constitutes culture. The 'culture of individualism' is taken as the gold standard in the SDT approach, without acknowledging that it may not be universal across societies, or mark the endpoint of societal development.

Eric D. Widmer's chapter directs our attention to how we theorise 'family'. The structuralist approach - which is most pervasive in the writing of Parsons - adopts a narrow definition of what constitutes the family: namely, the co-residential, married, heterosexual couple with their biological children. In many respects, we have overcome structuralism. However, much of present research on family diversity shares with this approach a commitment to the household perspective. The 'configurational approach' overcomes this shortcoming. From this viewpoint, the family is seen as a dynamic entity of individuals that changes across time, and that expands beyond the narrow thresholds of the household unit. The family is subject to a constant process of construction by its varying members. The 'we-ness' - and, thus, the belonging to a family - is a dynamic and ambivalent process. It entails positive as well as negative interactions, which is most obvious in the case of post-separation families (see also the chapter by Zartler). The configuration approach is strongly linked to classical network analysis, including the methods and techniques that study and visualise the ties and exchanges that exist between family members (see also the chapter by Viry and Herz). 
Dirk Konietzka and Michaela Kreyenfeld summarise the evolution of the life course approach and its contribution to family sociology. The foundational work of the life course framework was laid by the pioneering studies of Glen Elder. This work emphasised the importance of 'time' for understanding social change and human behaviour. Life has a history: i.e., how we act today is related to our past experiences. Behaviour is also anchored in time, because individuals are located in a generational hierarchy. For family research, the introduction of the life course approach was fundamental, as it shifted the perspective from a more static to a more dynamic view of family behaviour. It is because of the contributions of the life course approach that scholars now pay particular attention to the timing and the transitions of family events, such as the timing of birth, marriage, or divorce. Life course research has clearly evolved in tandem with event-history analysis and, more recently, with sequence analysis. It has also motivated large-scale longitudinal data collection. Although the life course approach originates in the United States-based studies of Glen Elder, there is a 'European' interpretation of the framework that pays particular attention to the role of contextual factors, such as welfare state regulations, for shaping life course patterns.

\subsection{New Perspectives in Family Research}

As was alluded to above, advances in theory have been rather slow. In the absence of novel theories, we tend to revert to theoretical concepts that evolved decades ago. While these theoretical concepts may claim that they are universal and applicable to all societies and time periods, it is clear that they evolved against a specific societal backdrop, and responded to a particular societal problem or puzzle. This is very evident for the SDT approach, which was formulated in response to the changes in family patterns that have occurred since the late 1960s in Western Europe. While theoretical progress has been slow, contemporary family sociology benefits greatly from innovative data collection and sophisticated statistical modelling, and, more generally, from advances in information technology. The latter advances have allowed us not only to process ever larger datasets, but to visualise family behaviour with new and appealing techniques. It is possible that further progress in family sociology will be spurred by the challenges and peculiarities of our age. One of these trends is surely the digitalisation of science and society.

Nicolas M. Legewie and Anette E. Fasang introduce the reader to the emerging field of digital family sociology. Compared with other disciplines - and particularly compared with political science, in which the 'scraping' of social media data is now common practice - family sociologists have been rather slow to tap into this new area of research. The authors of this chapter bring our attention to the potential of these data. They explain that 'big data' is often used as a catchall term that covers very different types of data. Two types can be broadly distinguished: digital trace data that emerge as a by-product of internet use (such as Facebook data), and purposefully collected digital data (in particular, data collected through smartphone applications). These types of data could be used in innovative ways in family sociology and family demography. In family demography, digital trace data may become an important basis for predicting fertility trends. Compared with the data from more conventional sources, digital trace data are 'real-time data'. Thus, the use of such data can help researchers overcome the shortcomings of classical survey data and administrative data (such as birth registers), including the long time lags between data collection and data analysis. Digital trace data also represent an untapped resource for time use analysis, including the analysis of the time use of 
couples and of post-separation families. However, the authors of this chapter also alert us to the many unresolved ethical issues associated with the collection and use of these types of data.

Laura Bernardi introduces the reader to novel pathways for qualitative research in family sociology. Qualitative and ethnographic studies have always been key for understanding the meaning and motivations that people attach to family behaviour. Qualitative research operates as a magnifying glass; it teases apart the subjective and objective meaning that we attach to our actions. Moreover, qualitative research has long been seen as a useful way of collecting biographical information. However, a 'panel perspective' was absent from most prior qualitative studies. Laura Bernardi advocates bringing the panel perspective into qualitative research using a 'qualitative longitudinal research' approach. Under this approach, biographical interviews are collected repeated times over a significant period of the life course. This will enable the researcher to examine how individuals assign meaning to their actions, and how this meaning changes as time passes, and their circumstances alter.

Gil Viry and Andreas Herz provide an overview as well as practical examples from network analysis in family sociology. Since the pioneering work of Granovetter (1973), network analysis has been one of the standard tools of family sociology. While it is, therefore, an almost classical perspective, a lot of progress has been made in the field in recent years. Much of this progress can be attributed to advances in computer technology, which provided us with more sophisticated ways of visualising networks and their evolution across time. However, the revival of the network approach in family sociology must also be seen in conjunction with the changes in family behaviour in the recent decades. It is no longer adequate to view the family as a static group that is locked in a household unit (see also the chapter by Widmer). Family relations are dynamic, and extend across household entities. The network approach is able to capture and address the corresponding complexity of family diversity. The authors of this chapter suggest various possible avenues for future research in this area, in particular the shift away from an ego-centric perspective and towards a more socio-centric perspective in the analysis of family ties.

\subsection{Family Diversity and Family Change}

The study of 'family diversity' has a long tradition that is partially rooted in national household statistics that map household structures based on census or micro-census data. National statistical offices have been rather slow to include family forms, such as cohabitation and living-apart-together relationships in their official classification systems. Social science surveys have generally been able to overcome this shortcoming. They have also opened up opportunities to examine how family diversity unfolds across the life course. Moreover, sequence analysis has been an important tool for advancing research on the 'de-standardisation' of the family life course. Most studies take the nuclear family - defined as a married and heterosexual couple with their biological children - as a starting point for measuring diversity. Disagreement still exists about how to typify and label family forms beyond the allegedly 'standard' or 'normal' family form. 'Unconventional', 'alternative', or 'non-traditional' are all contested terms, as they are based on the premise that a certain norm dominates.

Josef Ehmer provides an account of historical perspectives on family change and family diversity. He reminds us that contemporary research tends to overemphasise the present, and often perceives the past as a monolithic entity. As a result, we tend to ignore the diverse family forms that existed in pre-industrial times. What we erroneously label as 'modern family forms' 
- such as stepfamilies and lone parenthood - existed throughout all historical periods. Scholars of family history also remind us that we sometimes adopt a simplified view of the prevalence of large and extended families during pre-industrial times. Extended families existed in some parts of Europe, but they were never as numerous as is often believed. Furthermore, the nuclear family is not an 'invention' of modern times, as it was a common family form in many parts of Europe before the Industrial Revolution. The most salient difference between families in pre- and post-industrial Europe is that in the former period, non-family members, such as lodgers or servants, were more likely to be part of the household unit. Ehmer also underlines in his chapter that the historical perspective casts a nuanced light on women's role in society, suggesting that the degree to which family structures in historical Europe were patriarchal varied greatly. Thus, the position of women in the family, and, more generally, in society varied considerably across time and space, and was most evident in differences in inheritance rules and property rights.

Tomáś Sobotka and Caroline Berghammer provide a demographic account of the major changes in family behaviour and family diversity across European countries in more recent decades. The major changes that have occurred during the second half of the twentieth century in Europe have inspired the SDT theory. Many of the features that were described in this concept still adequately describe patterns of family behaviour in contemporary Europe, which include increasing ages at first childbearing, high divorce rates, and the spread of cohabitation. These trends and patterns have led to the emergence of a diversity of family forms beyond the nuclear family, and are already well documented. It is less well known that European societies seem to be moving closer together in terms of family behaviour and family structures. While there were previously large cross-country differences in the age at childbearing, today, the median age at which women have their first child is now around age 30 in most European countries. In addition, the differences in divorce rates and the prevalence of cohabitation are narrowing, as the levels in the Southern European countries are 'catching up' to those in other parts of Europe. A similar catch-up process can be observed for childlessness and low fertility. While fertility remains low in German-speaking countries, there are some signs that this trend may be reversing. Meanwhile, childlessness continues to be higher in Southern European countries than elsewhere in Europe. A puzzling recent development is the decline in birth rates in the Nordic countries.

Chia Liu and Albert Esteve complement the demographic account of Sobotka and Berghammer by providing an empirical investigation of family forms in contemporary Europe. The overview highlights that regional differences still characterise Europe to some degree. While there has been a slight postponement in leaving home that may be related to the global financial crisis, the co-residence of young adult children and their parents is rare in Western and Northern Europe. Southern and Eastern European countries, most notably Italy, deviate from this pattern, as the children in these countries tend to leave the parental home late; often not until they move in with a partner or spouse. High and growing rates of union dissolution affect the living arrangements in most countries. Children often stay with their mother after a separation. As a result, men are less likely than women to be living with their children. Overall, singlehood in adulthood has become more prevalent across Europe over time. The main drivers of this development are childlessness and union dissolution. However, we also see some decreases in singlehood at older ages. Previously, there were large gender differences in single living at advanced ages. As men's life expectancy has increased disproportionately in years, the gender gap in singlehood has decreased somewhat. 
Pearl A. Dykstra's chapter zooms in on the living arrangements at higher ages. Living arrangements at ages 60 and older have become more diverse, because the separation, divorce, and re-partnering rates at these ages have increased across time. However, we still know relatively little about the ramifications of union disruption at higher ages, and of how such break-ups affect the social and financial well-being of older people. An important dimension of the living arrangements of older people is institutional living at advanced ages. The patterns of institutional living in Europe have converged somewhat across time. Dykstra sees two processes at play in this trend: first, public spending on residential care has been curtailed in countries where institutionalised care was already widespread; and, second, other countries, and particularly Southern and Eastern European countries, have increased their efforts to expand residential care for the elderly.

\subsection{Family Transitions in the Life Course}

Quantitative family sociology has been dominated by the analysis of single life course transitions, such as the analysis of first birth, first marriage, first divorce, or re-partnering. On the one hand, we can lament that the analysis of these single life course transitions leads to a fragmentation of research perspectives. On the other hand, the focus on a specific event in the life course enables us to cast a nuanced light on family behaviour, and to distinguish the many factors that determine a specific family transition. The rich longitudinal data that have become available across time have also enabled us to model the precursors of family transitions, including investigations that shed light on whether intentions and attitudes are stable across the life course, and how these attitudes affect subsequent family behaviour.

Jan Van Bavel introduces the reader to theories and studies on partner formation. Partnership formation, marriage, and cohabitation are critical life course decisions. They are turning points in an individual's life, because in addition to having a profound impact on the person's emotions and mental well-being, they influence his/her social status and economic standing. In order to formulate theories about partnership behaviour, scholars have reverted to the concept of marriage and partner markets. Partner choices are regarded as rational decisions that are influenced by the needs that a partnership fulfils, the preferences of an individual, and the opportunities and barriers that constrain or enable mating. Scholars disagree about how the increasing education and emancipation of women has changed mating patterns. Women have reached parity in educational attainment in many European countries. However, the repercussions of this development for partner formation have been less profound than was widely expected. The share of couples in which the woman earns more than the man is growing. Furthermore, women's economic standing has become a positive trait on the partner market that influences women's chances of mating in a positive way. However, women's earnings have not reached parity with men's in any European country. As a result, it is still much more common for a woman than for a man to 'partner up' (select a partner with a higher income).

Dimitri Mortelmans provides an overview of the large body of research that has examined union dissolution. While prior research has been limited to the study of marital dissolution, scholars are increasingly including the dissolution of cohabiting unions in their investigations. Nevertheless, official statistics have not kept up with this development, as official sources mainly report marital dissolution rates, which provide an incomplete and often misleading picture of the stability of unions in European countries. So far, there is hardly any research on living-apart-together relationships and their stability. An important finding of recent empiri- 
cal research is that union dissolution is closely tied to patterns of social inequality. There is increasing evidence that the relationship between education, income, and union stability is about to change in a profound manner. Whereas, previously, education was only loosely or even positively correlated with divorce and union instability, the association seems to have flipped, with the risk of divorce and separation being concentrated in the lower social strata of society.

Ann Berrington focuses more closely on the above-mentioned increases in the age at first birth that has occurred across Europe (see the chapter by Sobotka and Berghammer). In particular, Berrington highlights that we now have rich longitudinal data on people's fertility intentions that allow us to examine their stability across time; how they change in response to changing constraints; and whether and, if so, under what conditions they lead to action. This type of research has also made significant progress in formulating theories regarding fertility behaviour, mostly by drawing on concepts and theories from psychology. Berrington postulates that advances in this area could be made by adopting a couple perspective in empirical investigations. Another potential avenue for future research is the inclusion of biological factors in the analysis of fertility processes.

Gunnar Andersson's chapter addresses the family transitions - and particularly the fertility transitions - among migrant populations. Like Nauck (see above), Andersson expresses a certain discomfort with prior studies in this area of research. He argues that these studies often overemphasised the role of 'culture' when seeking to explain the behaviour of migrants. While socialisation and cultural traits are assumed to be the key forces that guide migrant behaviour, too little attention is paid to the role of constraints in the destination country. However, some innovative data collection projects have been launched in this area. Comparisons of migrants of the same origin living in different countries of Europe have sharpened our understanding of how the welfare state context and country-specific regulations affect migrants' family well-being and family behaviour. Andersson also points out that official vital statistics data are too limited to map the birth and family dynamics of migrants. As these data only capture the migrants' behaviour after migration, they provide an inconclusive and misleading picture. Thus, using survey data that provide complete migration and family biographies, including information on the migrants' lives before migration, may be more constructive in this context. These data often show that the birth rates of female migrants increase sharply around the time of migration. Further research is needed to determine the factors that lead to these patterns; how they differ by gender, country of origin, and destination country; and how they have changed across time.

\subsection{Intimate and Intergenerational Relationships}

Intergenerational relationships are core areas of family research. Having knowledge about the support that is provided across generations is crucial for understanding the fabric of our society. Large-scale longitudinal datasets, such as the Survey of Health, Aging and Retirement in Europe, have generated a rich battery of findings on the organisation and practices of many exchanges that occur across the generations, including financial transfers (inter-vivo) as well as care support (e.g., Albertini and Kohli 2009, 2013). As longevity has been growing in European countries, this field of research has clearly expanded its focus. While much of the prior research on this topic focused on the intergenerational relationships of two adjacent generations, recent attention has shifted to the analysis of more distant generations, such as 
grandparent-grandchildren relationships. Moreover, the high and increasing divorce and separation rates have inspired a new body of research that has examined the relationship between separated parents and their children, as well as the intergenerational relationships in stepfamilies (e.g., Steinbach and Hank 2016).

Jan Skopek provides a demographic perspective on grandparenthood. In the long historical perspective, the chances of becoming a grandmother or grandfather have increased substantially across time. Grandparents can enjoy more time with their grandchildren than ever before in history. Recent changes in family behaviour, such as increasing childlessness and fertility postponement, are, however, forces that work in opposite directions. Skopek also points out that strong gender and country differences exist in the experience of grandparenthood. Women's life expectancy is higher and women have children at lower ages than men. As a result, grandmothers enjoy more time with their grandchildren than grandfathers. Country differences in the 'exposure' to grandparenthood exist because of differences in longevity and childbearing patterns. Up to the 1970s, the 'shared lifetime' of grandchildren and grandparents went up in European countries, but this trend seems to have levelled off for some countries in recent years.

Ulrike Zartler gives us an account of one of the emerging literatures that deals with parentchild relationships after separation and divorce. A significant body of empirical research has amassed that has examined how children cope with the divorce and separation of their parents, the feelings that a parental break-up evokes, and the factors that may buffer the stress and adverse consequences of the break-up. Zartler calls for more rigorous attention to the child's perspective in the divorce and separation proceedings. This perspective may also generate important insights into the ambivalence about what constitutes family, as the definition may vary greatly between children and (step)parents in post-separation families. Research of this kind adds considerably to previous studies that viewed family as a dynamic entity that is constantly constructed via everyday interactions (see the chapters by Viry and Herz as well as by Widmer in this volume). Substantial controversy still exists about the consequences of divorce and separation for children and parent-child relationships. While some scholars tend to emphasise the adverse effects that divorce and separation have on the well-being of children, other scholars call for the better 'management' of multi-local parenting. Zartler also points out that national (and supranational) policies play a pivotal role in shaping post-separation family life.

Karl Lenz and Marina A. Adler's contribution focuses on a much neglected area of research in the field of intimate and intergenerational relationship: namely, love, emotions, and sexuality. The emergence of 'romantic love' during the nineteenth century has been well documented. Sociological research - in particular through the writings of Luhmann - has also led us to understand love as a 'culture-bound phenomenon'. There has been less sociological research on other types of emotions, such as anger, hate, and guilt. The sociological studies that have examined the consequences of divorce and separation represent an exception (see, e.g., Moore 2020 as well as Zartler in this volume). Interestingly, in the past, sexuality and love/emotions have been seen as separate fields of inquiry. Lenz and Adler call for a better integration of these two strands of research.

\subsection{New Insights into the Division of Work in Families}

It is a stylised fact that increasing female employment rates have not been accompanied by equal shifts in the division of household labour - a development that recently prompted schol- 
ars to argue that the gender revolution is 'stalled' or 'incomplete' (Esping-Andersen 2009; Hochschild and Machung 1989). This claim was followed by a discussion of what changes might occur once the gender revolution was completed (Goldscheider et al. 2015). Could low fertility, high childlessness levels, and high divorce rates be reversed if greater gender equality was achieved? What is the scope for a more equal division of child care between men and women? Will fathers and mothers ever reach parity in labour market outcomes and time investments in child care?

Anna Matysiak and Ewa Cukrowska-Torzewska emphasise in their contribution that in many countries, women have been able to reach parity with men in terms of education. In addition, the employment rates of women have increased significantly. Regardless of this development, large gender differences persist in terms of working hours, income, and labour market status. These differences are conventionally attributed to occupational segregation and discrimination on the labour markets. A large body of research is also devoted to the pivotal role of family policies - in particular, child care and parental leave policies - in explaining the differences in the work patterns of mothers and fathers across countries. However, the authors also point out that we still lack a deep understanding of how gender equality is influenced by labour market policies and recent labour market developments, such as technological changes induced by digitalisation. Moreover, it is still uncertain how the global financial crisis, as well as the Covid-19 crisis, have shifted the economic foundations of the family. While it seems clear that the traditional earner model is a fragile family model in times of crisis, how such crises have affected gender equality and couples' division of work is less clear.

Oriel Sullivan's chapter summarises the results of an analysis of time use diary data that cover several European countries, and that contain information for several decades. She confirms that allegedly tedious and repetitive household tasks, such as cleaning and cooking, tend to remain gendered in most European societies. However, men are now more active in child-care activities than they were in previous decades, even though fathers' participation in paid employment has remained largely unchanged. The Nordic countries continue to be the vanguards of 'involved fatherhood'. However, the country differences have narrowed a pattern that has been observed for other areas of family life as well, such as the timing of first childbirth and the prevalence of divorce (see above).

The birth of the first child is a key turning point in a person's life course, and often leads to a gendered work and care pattern. Daniela Grunow illustrates that this tends to occur even in couples in which the woman had previously earned a higher income or had better job prospects than her partner. She emphasises that it is often not the economic rationale alone that determines how a couple's family life is organised, but the normative prescriptions about what constitutes 'good' motherhood and fatherhood in a society. While these patterns differ across countries, it is clear that gender prescriptions continue to have a strong grip on our care and employment behaviour.

Prior studies on the division of housework and care have mainly focused on heterosexual couples. As well as representing a family form that has attracted the attention of researchers studying the diversity of living arrangements, same-sex couples constitute a suitable test case for analysing gender role theories. Marie Evertsson, Madeleine Eriksson Kirsch, and Allison Geerts summarise in their chapter the qualitative as well as quantitative studies in this area of research. The evidence suggests that while there is some specialisation in these families, same-sex parents tend to organise their work and care responsibilities more equally than different-sex parents. In heterosexual partnerships, an initial disadvantage, such as having 
a lower wage, often perpetuates traditional care patterns. This does not seem to be the case for same-sex couples, as they are better able to restore equality in the division of household tasks and paid work.

When seeking to provide a theoretical basis for work and care patterns, it is common among sociologists to draw on the classical 'specialisation model' of Gary Becker. This model emphasises the 'efficiency gains' of an unequal division of household labour and paid employment. Wendy Sigle reminds us in her chapter that we should be careful when drawing on this outdated framework. Becker's specialisation model makes assumptions that are similar to those of the structural-functional theories of sociology. As in these models, the point of departure of Becker's model is the belief that an unequal division of care and paid work is a superior and efficient way to organise family life. Sociologists have developed alternative theories, such as the 'doing gender' approach that highlights how internalised norms determine gendered work-care patterns (West and Zimmerman 1987). However, these approaches are often employed only as a counterpoint to the specialisation model, and have not led to a real paradigm shift.

\subsection{Family and Society}

Family behaviour and family well-being are strongly influenced by larger societal trends (such as individualisation, digitalisation, migration, and growing social inequality), and by significant period effects (including the global financial crisis, or, more recently, the Covid-19 crisis). Social policies may respond to these trends, and help to ameliorate some of the adverse consequences that large economic and societal trends have for family well-being. National policies may facilitate or hinder certain developments. This is most evident in the area of ART. All countries are committed to increasing family well-being and reducing family and child poverty. Despite these shared commitments, European countries differ sharply in the approaches they use to accomplish their goals. Europe is still a 'patchwork quilt' with regard to family support and family policies, despite some modest efforts of the European Union to harmonise policies, such as its target to increase child-care availability for children under the age of three.

Jonathan Bradshaw and Rense Nieuwenhuis provide an overview of child poverty in European countries. The harmonised Eurostat dataset, with its rich pool of poverty indicators, allows us to shed a nuanced light on variations in family well-being across countries. However, depending on the indicators used, the country ranking differs greatly. Overall, child poverty seems to have risen disproportionately since the global financial crisis. Bradshaw and Nieuwenhuis illustrate the importance of states implementing measures for reducing child poverty in response to this development. Mothers' integration into employment is important to shield families from poverty. However, the authors also alert us that in many European societies, a growing fraction of the population are 'working poor'.

Jasmin Passet-Wittig and Martin Bujard provide an account of the research in the area of MAR. MAR includes ART as well as 'softer' measures, such as assisted insemination or hormonal treatments, that enable couples to fulfil their desires to have children. Up to today, there are large discrepancies in how European countries regulate MAR and, more specifically, ART. This variation is probably most evident for surrogacy, which is allowed in only a few European countries, such as the United Kingdom and the Czech Republic. The great variation that exists in the legal frameworks raises important ethical questions, not least because 
cross-border travel to access ART services can hardly be controlled. Moreover, the funding of MAR treatments differs greatly across countries. As a result, some countries are laggards in this development, while others are taking the lead. Interestingly, there is no clear regional pattern or any variation that matches any prior categorisation. Currently, Denmark, Spain, Greece, and the Czech Republic are taking the lead in ART. Apart from these large country differences, there are concerns about social differences in access to and usage of MAR.

Laura Merla, Majella Kilkey, Raelene Wilding, and Loretta Baldassar provide an overview of the state of the art in transnational family research. Transnational family research marks an important paradigm shift in migration research. Whereas, previously, migration was often conceptualised as a 'one-shot event', the 'transnational turn' has sharpened our awareness that migration is a more complex undertaking. Migration may be temporary or circular. Some migrants may cut their ties with their country of origin, but in most cases, close ties and interactions with people in the country of origin continue beyond migration. This is particularly likely to be the case if close family members, such as children, partners, or spouses, remain in the country of origin. Family networks as well as care for children and for the elderly may extend beyond national borders. Advances in information and communication technologies, such as text messaging and video calls, have made it easier for migrants to stay in close contact with family members in the country of origin (or in other countries or places). Transnational families raise important social policy issues, such as the portability of pension rights, the transferability of family benefits across borders, and access to care facilities for transnational families.

\section{REFERENCES}

Albertini, M. and M. Kohli (2009), 'What childless older people give: Is the generational link broken?', Ageing and Society, 29, 1261-74. doi:10.1017/S0144686X0999033X.

Albertini M. and M. Kohli (2013), 'The generational contract in the family: An analysis of transfer regimes in Europe', European Sociological Review, 29 (4), 828-40. doi:10.1093/esr/jcs061.

Bittman, M., P. England, L. Sayer, N. Folbre, and G. Matheson (2003), 'When does gender trump money? Bargaining and time in household work', American Journal of Sociology, 109 (1), 186-214. doi: $10.1086 / 378341$.

Cherlin, A. (2006), 'On single mothers “doing” family', Journal of Marriage and Family, 68 (4), 800-3. www.jstor.org/stable/4122874.

Coleman, D. (2004), 'Why we don't have to believe without doubting in the "second demographic transition”, some agnostic comments', Vienna Yearbook of Population Research, 2 (1), 11-24. doi:10 $.1553 /$ populationyearbook2004s 11 .

Dahrendorf, R. (1965), Homo Sociologicus, Opladen: Westdeutscher Verlag.

Déchaux, J.-H. (2009), Sociologie de la Famille, Paris: La Découverte.

Esping-Andersen, G. (1999), Social Foundations of Postindustrial Economies, Oxford: Oxford University Press.

Esping-Andersen, G. (2009), The Incomplete Revolution: Adapting Welfare States to Women's New Roles, Cambridge: Polity Press.

Fasang, A.E., J. Huinink, and M. Pollmann-Schult (2016), 'Aktuelle Entwicklungen in der deutschen Familiensoziologie: Theorien, Daten, Methoden', Zeitschrift für Familienforschung, 28 (1), 112-43. doi:10.3224/zff.v28i1.22923.

Glick, P.C. (1955), 'The life cycle of the family', Marriage and Family Living, 18, 3-9.

Goldscheider, F., E. Bernhardt, and T. Lappegård (2015), 'The gender revolution: A framework for understanding changing family and demographic behavior', Population and Development Review, 41 (2), 207-39. doi:10.1111/j.1728-4457.2015.00045.x. 
Granovetter, M.S. (1973), 'The strength of weak ties', American Journal of Sociology, 78 (6), 1360-80. https://link.springer.com/chapter/10.1007/978-3-030-44575-1_7.

Hochschild, A.R. and A. Machung (1989), The Second Shift: Working Parents and the Revolution at Home, New York: Viking.

Jurczyk, K., A. Lange, and B. Thiessen (eds) (2014), Doing Family: Familienalltag heute, Weinheim: Juventa.

Konietzka, D., M. Feldhaus, M. Kreyenfeld, and H. Trappe (2020), 'Intimate relationships and the family', Soziale Revue.

Lesthaeghe, R. (1995), 'The second demographic transition in western countries: An interpretation', in K. Oppenheim Mason and A.-M. Jensen (eds), Gender and Family Change in Industrialized Countries, Oxford: Clarendon Press, pp. 17-62.

Lesthaeghe, R. (2010), 'The unfolding story of the second demographic transition', Population and Development Review, 36 (2), 211-51. doi:10.1111/j.1728-4457.2010.00328.x.

Lesthaeghe, R. and J. Surkyn (1988), 'Cultural dynamics and economic theories of fertility change', Population and Development Review, 14 (1), 1-45. doi:10.2307/1972499.

Lewis, J. (1992), 'Gender and the development of welfare regimes', Journal of European Social Policy, 2 (3), 159-73. doi:10.1177/095892879200200301.

Lundberg, S. and R.A. Pollak (1994), 'Noncooperative bargaining models of marriage', American Economic Review, 84 (2), 132-7. www.jstor.org/stable/2117816.

McLanahan, S. (2004), 'Diverging destinies: How children are faring under the second demographic transition', Demography, 41 (4), 607-27. www.jstor.org/stable/1515222.

Moore, E. (2020), 'Divorce, emotions, and legal regulations: Shared parenting in a climate of fear', in M. Kreyenfeld and H. Trappe (eds), Parental Life Courses after Separation and Divorce in Europe, Cham: Springer, pp. 131-47. www.springer.com/gp/book/9783030445744.

Parsons, T. (1955), 'The American family: Its relations to personality and to the social structure', in T. Parsons and R.F. Bales (eds), Family, Society and Interaction Process, New York: Free Press, pp. 3-33.

Sainsbury, D. (1996), Gender, Equality, and Welfare States, Cambridge: Cambridge University Press.

Saraceni, C. and M. Naldini (2013), Sociologia della Famiglia, Bologna: Mulino.

Schneider, N.F. (2012), 'The future of the family in Europe: Diversity and convergence', in H. Bertram and N. Ehlert (eds), Family, Ties, and Care: Family Transformation in a Plural Modernity, Opladen: Barbara Budrich, pp. 225-39.

Stacey, J. (1996), In the Name of the Family: Rethinking Family Values in the Postmodern Age, Boston, MA: Beacon Press.

Steinbach A. and K. Hank (2016), 'Intergenerational relations in older stepfamilies: A comparison of France, Germany, and Russia', The Journals of Gerontology: Series B, 71 (5), 880-8. doi:10.1093/ geronb/gbw046.

Van de Kaa, D.J. (1987), 'Europe's second demographic transition', Population Bulletin, 42 (1), 3-57.

West, C. and D.H. Zimmerman (1987), 'Doing gender', Gender and Society, 1 (2), 125-51. www.jstor .org/stable/189945.

Whitehead, B.D. (1993), 'Dan Quayle was right', The Atlantic Monthly, April, 47-84. www.theatlantic .com/magazine/archive/1993/04/dan-quayle-was-right/307015/. 